\section{Submitted: 20.12.2020 Accepted: \\ Shear wave elastography in optic neuritis: diagnostic accuracy of the optic nerve and adjacent fat tissue values} 18.02.2021

Published: 16.08.2021

\author{
Keywords \\ multiple sclerosis, \\ optic neuritis, \\ optic nerve, \\ recurrent isolated \\ optic neuritis, \\ shear wave \\ elastography
}

\author{
Mustafa Devran Aybar' ${ }^{1}$ Onder Turna² \\ ${ }^{1}$ Radiology Department, Medigold Sultan Hospital, Turkey \\ ${ }^{2}$ Radiology Department, Mehmet Akif Ersoy Training and Research Hospital, Turkey \\ Correspondence:Dr Mustafa Devran Aybar,e-mail:mdaybar@gmail.com
}

DOI: $10.15557 / \mathrm{JoU} .2021 .0031$

\begin{abstract}
Introduction: In this study, we attempt to determine the diagnostic performance of shear wave elastography of the optic nerve and adjacent fat tissue in patients with optic neuritis. Methods: The study included a patient group consisting of 72 eyes of 36 patients who were diagnosed with unilateral optic neuritis, and an age-matched control group of 36 eyes of 18 healthy subjects. The patient group consisted of 25 multiple sclerosis patients and 11 recurrent isolated optic neuritis patients. The mean shear wave elastography values of the optic nerves and intraorbital fat tissue adjacent optic nerves were recorded using $\mathrm{m} / \mathrm{s}$ and $\mathrm{kPa}$ as units. ROC curve analysis was performed, and the diagnostic accuracy of shear wave elastography values was determined. Results: The mean shear wave elastography values of the optic nerves with neuritis $(2.49 \pm 0.41 \mathrm{~m} / \mathrm{s}$ and $17.56 \pm 4.42 \mathrm{kPa})$ were significantly higher than the values of the contralateral normal optic nerves $(1.71 \pm 0.32 \mathrm{~m} / \mathrm{s}$ and $9.02 \pm 2.34$ $\mathrm{kPa})(p=0.006$ and $p=0.004$, respectively) in the optic neuritis group. The mean shear wave elastography values of intraorbital fat tissue adjacent optic nerves with neuritis $(1.87 \pm$ $0.32 \mathrm{~m} / \mathrm{s}$ and $9.65 \pm 1.12 \mathrm{kPa}$ ) were significantly higher than the values of the contralateral normal side $(1.47 \pm 0.27 \mathrm{~m} / \mathrm{s}$ and $6.78 \pm 1.14 \mathrm{kPa})(p=0.025$ and $p=0.022$, respectively) in the optic neuritis group. ROC curve analysis showed a high diagnostic accuracy for determining optic neuritis with shear wave elastography values of the optic nerves (AUC 0.955 [95\% CI, 0.933-0.978] in m/s and AUC 0.967 [95\% CI, 0.940-0.985] in kPa). Conclusions: Shear wave elastography may be an important alternative diagnostic tool in the diagnosis of optic neuritis.
\end{abstract}

\section{Introduction}

Optic neuritis (ON) is defined as inflammation of the optic nerve. It is mostly idiopathic, but can be associated with variable causes (demyelinating lesions, autoimmune disorders, infectious and inflammatory conditions $)^{(1,2)}$. Patients occasionally experience unilateral loss of vision, periocular pain, and impaired color vision. The inflammatory process usually occurs in a portion of the retrobulbar optic nerve, so the optic disc might be normal in adults ${ }^{(3,4)}$. Therefore, the diagnosis of $\mathrm{ON}$ is usually made clinically. Magnetic resonance imaging (MRI) is the most important tool to visualize the retrobulbar area which includes the optic nerve ${ }^{(5)}$. MRI examination of the optic nerve is technically challenging due to the size of the nerve, motions during the acquisition process, chemical shift artifacts, and cerebrospinal fluid (CSF) signal in the nerve sheath ${ }^{(6)}$. Computed tomography (CT) uses ionizing radiation and has limited applications (such as infections and neoplastic diseases). There is a need of a practical study for the diagnosis and follow-up of ON patients ${ }^{(7)}$. Elastography is a non-invasive ultrasonographic (US) technique for evaluating the elastic properties of tissues, and shear wave elastography (SWE) uses waves that are generated by transducers and interact with the tissue ${ }^{(8)}$.

In the present study, we attempt to determine the optic nerve findings and diagnostic performance of SWE as an alternative to MRI in patients with ON. 

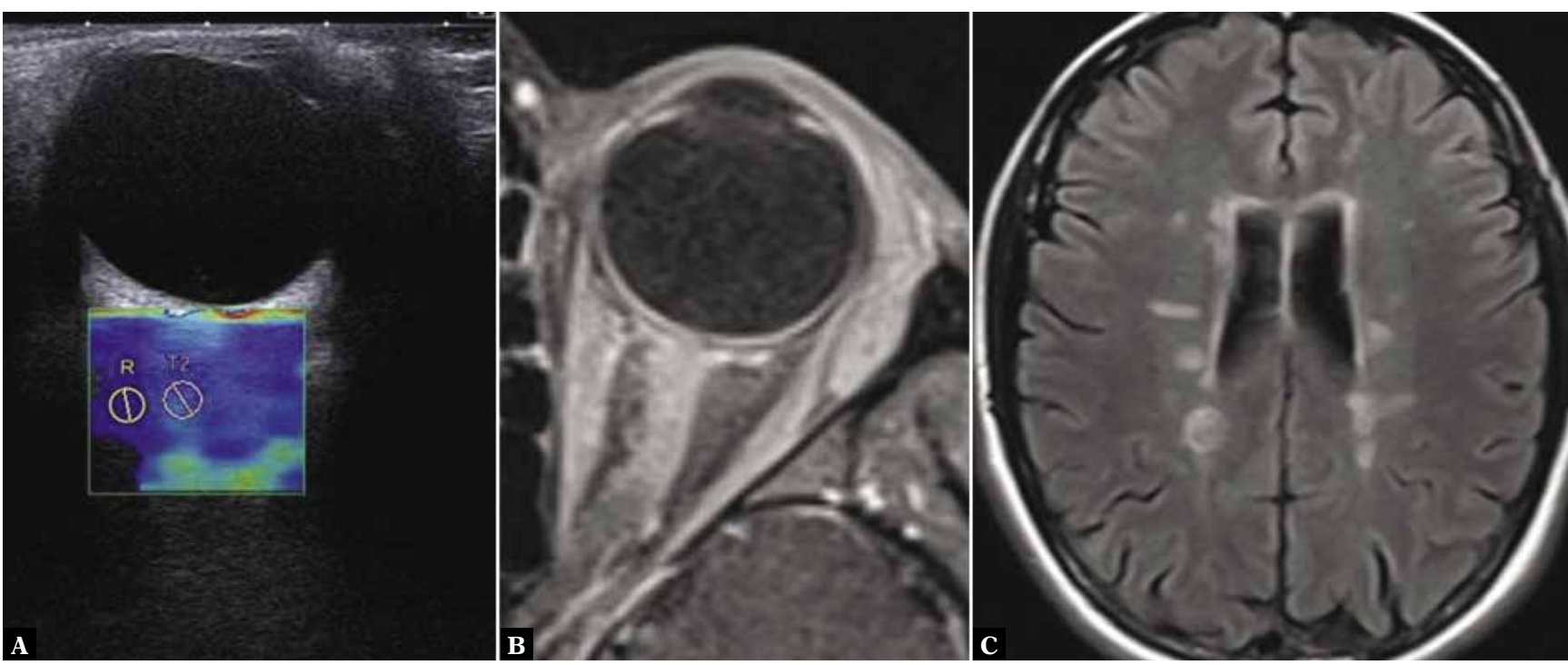

Fig. 1. A 25-year-old MS patient with left optic neuritis of 6 years' duration, 5 days after the onset of ON attack. A. SWE images of the optic nerve, adjacent fat tissue, and circular regions of interest, respectively with $2.49 \pm 0.41 \mathrm{~m} / \mathrm{s}$ and $17.56 \pm 4.42 \mathrm{kPa}$, and $1.87 \pm 0.32 \mathrm{~m} / \mathrm{s}$ and $9.65 \pm 1.12 \mathrm{kPa}$. B. T1-weighted image with contrast agent shows swelling and enhancement of the optic nerve. C. Axial FLAIR image showing periventricular-pericallosal plaque formations

\section{Material and methods}

The patients diagnosed with ON at our center between April 2017 and August 2019 were enrolled in the study. This prospective study was approved by the local ethics committee (ethical approval code: 20170103). Informed written consent was obtained from each patient, and the study was performed according to the World Medical Association Declaration of Helsinki. A total of 48 patients with $\mathrm{ON}$ who were diagnosed with ophthalmological and neurological findings and positive brain and orbital findings were selected for the study protocol.

The inclusion criteria of the patient group were: patients who were clinically suspected to have $\mathrm{ON}$, with a sudden onset of unilateral visual loss, severe ocular pain, dyschromatopsia within a few days or weeks of the onset of these symptoms, patients with relapsing-remitting MS, isolated ON without any clinical, radiological or laboratory signs of demyelinating diseases, autoimmune disorders or vasculitis, patients with unilateral thickened optic nerves with high T2 signal and contrast enhancements on brain or orbital MRI, and patients who were able to cooperate in the lying position with their eyes shut during ultrasonography and SWE assessment.

A total of 12 patients were excluded from the study protocol. The exclusion criteria in the patient group were: patients who were unable to undergo the examination in the lying position with their eyes shut $(n=2)$, patients with other systemic diseases affecting the eye or the optic nerve, such as systemic hypertension, diabetes mellitus or Behçet's disease $(n=3)$, patients with a history of ophthalmic surgery $(n=3)$, patients with glaucoma $(n=2)$, and patients with severe retinal or macular disease $(n=2)$.

Healthy subjects were chosen from those who did not have any clinical suspicion of $\mathrm{ON}$ or systemic conditions with optic nerve involvement with normal MRI findings. Ultimately, the study included a group of 36 patients [female $(\mathrm{F}) /$ male $(\mathrm{M})=$ 19/17] with a total of 72 eyes, who were diagnosed with unilateral $\mathrm{ON}$, and an age-matched control group of 18 healthy subjects $(\mathrm{F} / \mathrm{M}=10 / 8)$ with 36 eyes. The patient group consisted of 25 multiple sclerosis (MS) patients $(\mathrm{F} / \mathrm{M}=14 / 11)$ and 11 recurrent isolated ON (RION) patients $(\mathrm{F} / \mathrm{M}=5 / 6)$. Revised 2017 McDonald criteria were used for the MS diagnosis $^{(9)}$. Among RION patients, all laboratory tests including blood and CSF count, protein and glucose levels and oligoclonal band for demyelinating diseases, autoimmune disorders or vasculitis were negative. In addition, all other neurological findings and MRI findings were negative in this subgroup.

All of the brain and orbital MRI examinations of suspected ON were analyzed by a national and European-boarded radiologist (O.T) with an experience of 14 years in MRI examinations. A radiologist (M.D.A) with more than 14 years of grayscale US and more than 5 years of elastography experience performed all the US and SWE examinations. The patients were instructed to lie down comfortably in the supine position, with their eyes shut. The retrobulbar intraorbital segments of the optic nerves were examined using an ultrasound scanner capable of SWE measurements using a linear array transducer (14 MHz) (Aplio 500 Platinum; Canon, Japan). First, the observer assessed the optic nerve diameter on gray-scale US, then SWE examinations of each patient was applied in the axial plane with a double screen displayed B-mode and color-coded SWE images simultaneously. The color spectrum of SWE was adjusted in the range of 0-6.5 meter/second $(\mathrm{m} / \mathrm{s})$ and $0-80$ kilopascal $(\mathrm{kPa})$. Three measurements with one minute duration of each optic nerves and orbital fat tissue adjacent optic nerves were taken in circular regions of interest (ROIs) of 1.5 to $2.5 \mathrm{~mm}$ diameters. We always measured SWE of the optic nerves and orbital fat tissue exactly in the same place, $3 \mathrm{~mm}$ away from the optic disc. SWE of the orbital fat tissue was always measured in the same place, $2 \mathrm{~mm}$ on the right parallel side to the optic nerve measurement. 


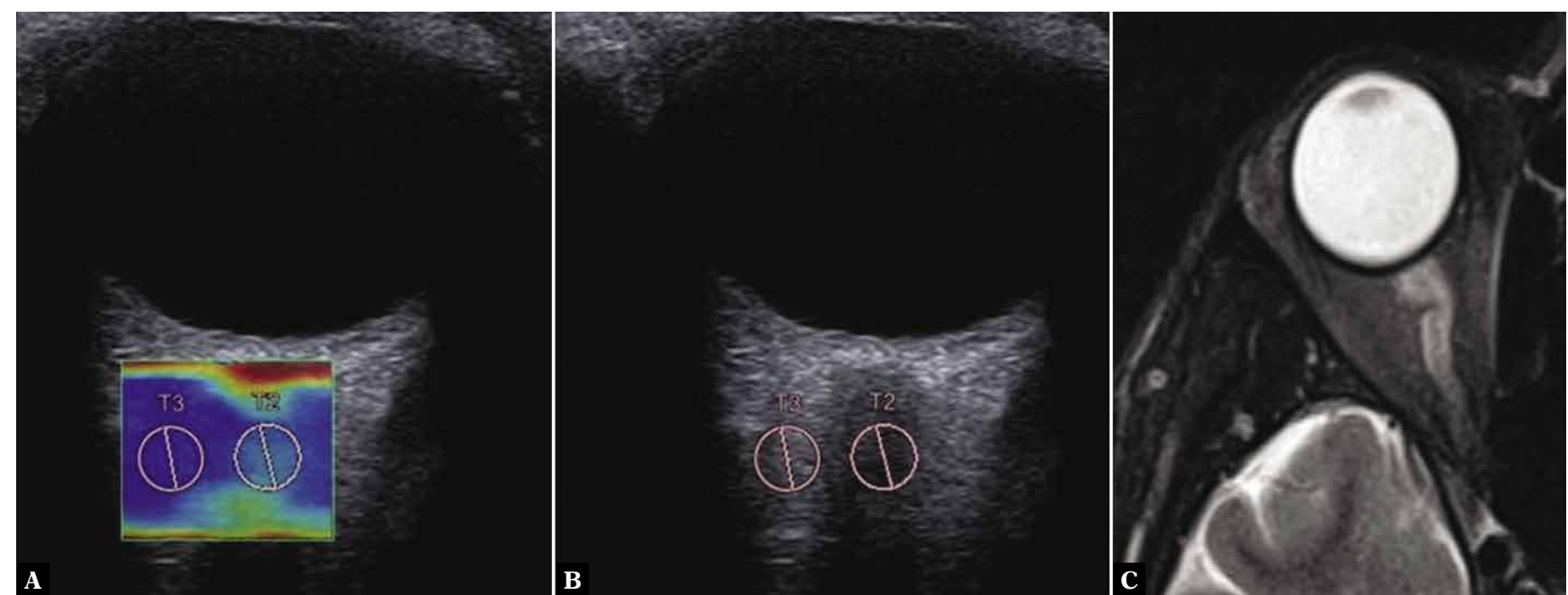

Fig. 2. A 32-year-old RION patient with right optic neuritis of 3 years' duration, 7 days after the onset of ON attack. A. SWE images of the optic nerve, adjacent fat tissue, and circular regions of interest, respectively with $2.46 \pm 0.31 \mathrm{~m} / \mathrm{s}-16.46 \pm 3.32 \mathrm{kPa}$ and $1.82 \pm 0.33 \mathrm{~m} / \mathrm{s}-$ $8.36 \pm 2.31 \mathrm{kPa}$. B. B-Mode US image showing swollen optic nerve. C. Axial T2W image showing swollen retrobulbar intra-orbital segment of the optic nerve, with a high T2 signal

The mean SWE values of the optic nerves ( $\mathrm{ROI}_{1}$ ) and intraorbital fat tissue adjacent optic nerves $\left(\mathrm{ROI}_{2}\right)$ were recorded using $\mathrm{m} / \mathrm{s}$ and $\mathrm{kPa}$ as units. All of the patients received therapy after their SWE evaluations. Fig. 1 and Fig. 2 show the SWE evaluation of the optic nerves and adjacent fat tissues.

\section{Statistical analysis}

SPSS version 16 was used to perform all statistical analyses. The variables were investigated using analytical methods (Shapiro-Wilk test) and visual techniques (histograms, probability plots) to determine whether they were normally distributed. The Student's t test was used to compare these variables. Correlations between the optic nerve diameter and SWE values, and between the duration of symptoms and SWE values, were calculated using the Pearson's test. Intraclass correlation coefficients (ICC) were used to determine intraobserver levels of agreement. An agreement was considered excellent for ICC $>0.80$, very good for $0.70-0.80$, good for $0.60-0.70$, fair for $0.40-0.60$, and poor for $<0.40$. Receiver operating characteristic (ROC) curve analysis was performed, and the diagnostic accuracy of SWE values was determined using the area under the curve (AUC) with a 95\% confidence interval. The highest value for Youden's index was accepted as the optimal cut-off value. Youden's index was obtained from the coordinates of the curve, and calculated by "J = max [SN + SP] -1 ". Optimal cut-off values with sensitivity and specificity were also investigated by ROC curve analysis. $\mathrm{P}$ values of $<0.05$ were considered statistically significant.

\section{Results}

The mean age of the patients with $\mathrm{ON}$ was $38.44 \pm 12.55$ years, and the mean age of the healthy controls was $35.45 \pm$ 11.33 years $(p>0.05)$. The mean diameter of the optic nerves with neuritis $(4.58 \pm 0.23 \mathrm{~cm})$ was significantly larger than that of the contralateral normal optic nerves $(3.66 \pm 0.58 \mathrm{~cm})$ $(p=0.016)$ in $\mathrm{ON}$ patients and that of the normal optic nerves in the healthy group $(3.54 \pm 0.43 \mathrm{~cm})(p=0.019)$. There was no significant difference between the normal contralateral side of the ON patients and the healthy group with regard to the mean diameter of the optic nerves $(p>0.05)$. There was no statistically meaningful difference in the mean diameter of the optic nerves with neuritis between the MS patients $(4.59 \pm 0.13 \mathrm{~cm})$ and RION patients $(4.54 \pm 0.22 \mathrm{~cm})(p>0.05)$. The mean time of disease duration was $9.33 \pm 5.47$ years in MS patients, and $7.38 \pm 4.36$ years in RION patients, and no significant difference was observed between these two parameters $(p>0.05)$. There was no statistically significant difference between the mean time of the onset of ON attack in MS patients (7.52 \pm 3.48 days $)$ and in RION patients $(6.55 \pm 4.16$ days $)(p>0.05)$.

The mean SWE values of the optic nerves with neuritis $(2.49 \pm 0.41 \mathrm{~m} / \mathrm{s}$ and $17.56 \pm 4.42 \mathrm{kPa})$ were significantly higher than the values of the contralateral normal optic nerves $(1.71 \pm 0.32 \mathrm{~m} / \mathrm{s}$ and $9.02 \pm 2.34 \mathrm{kPa})(p=0.006$ and $p=0.004$, respectively) in the $\mathrm{ON}$ group. The mean SWE values of the optic nerves with neuritis in the $\mathrm{ON}$ group exceeded the mean values in the healthy group (1.69 $\pm 0.25 \mathrm{~m} / \mathrm{s}$ and $9.42 \pm 2.24 \mathrm{kPa})(p=0.003$ and $p=0.015$, respectively) (Tab. 1 and Tab. 2). There was no significant difference between the normal contralateral side of $\mathrm{ON}$ patients and the healthy group with regard to the mean SWE values of the optic nerves $(p>0.05)$. No significant difference was observed between MS patients and RION patients in terms of the mean SWE values of the optic nerves with neuritis $(2.50 \pm 0.21 \mathrm{~m} / \mathrm{s}-19.26 \pm 4.11 \mathrm{kPa}$ and $2.46 \pm 0.31 \mathrm{~m} / \mathrm{s}-16.46 \pm 3.32 \mathrm{kPa}$, respectively) $(p>0.05)$. The intraobserver agreement for SWE values of the optic nerves was excellent, with an ICC of 0.90 [95\% CI, 0.865-0.945].

The mean SWE values of intraorbital fat tissue adjacent optic nerves with neuritis $(1.87 \pm 0.32 \mathrm{~m} / \mathrm{s}$ and $9.65 \pm 1.12 \mathrm{kPa})$ were significantly higher than the values of the contralateral normal side $(1.47 \pm 0.27 \mathrm{~m} / \mathrm{s}$ and $6.78 \pm 1.14 \mathrm{kPa})$ 
Tab. 1. Comparison of the mean optic nerve diameter and SWE values between the ON group with neuritis and the healthy control group ( $n=$ number of eyes)

\begin{tabular}{|c|c|c|c|}
\hline & $\begin{array}{c}\text { ON group, } \\
\text { neuritis side } \\
(\boldsymbol{n}=\mathbf{3 6})\end{array}$ & $\begin{array}{c}\text { Healthy control } \\
\text { group } \\
(\boldsymbol{n}=\mathbf{3 6})\end{array}$ & $\boldsymbol{p}$ \\
\hline $\begin{array}{c}\text { Optic nerve } \\
\text { diameter }\end{array}$ & $4.58 \pm 0.23 \mathrm{~cm}$ & $3.54 \pm 0.43 \mathrm{~cm}$ & 0.016 \\
\hline $\begin{array}{c}\text { Optic nerve } \\
\text { SWE value }\end{array}$ & $\begin{array}{c}2.49 \pm 0.41 \mathrm{~m} / \mathrm{s} \\
\text { and } \\
17.56 \pm 4.42 \mathrm{kPa}\end{array}$ & $\begin{array}{c}1.69 \pm 0.25 \mathrm{~m} / \mathrm{s} \\
\text { and } \\
9.42 \pm 2.24 \mathrm{kPa}\end{array}$ & $\begin{array}{c}0.006 \\
\text { and } \\
0.004\end{array}$ \\
\hline $\begin{array}{c}\text { Fat tissue } \\
\text { adjacent optic } \\
\text { nerve SWE } \\
\text { value }\end{array}$ & $\begin{array}{c}1.87 \pm 0.32 \mathrm{~m} / \mathrm{s} \\
\text { and }\end{array}$ & $\begin{array}{c}1.42 \pm 0.16 \mathrm{~m} / \mathrm{s} \\
\text { and }\end{array}$ & $\begin{array}{c}0.025 \\
\text { and } \\
0.65 \pm 1.12 \mathrm{kPa}\end{array}$ \\
$6.57 \pm 1.15 \mathrm{kPa}$ & 0.022 \\
\hline $\begin{array}{l}\text { ON - optic neuritis; SWE }- \text { shear wave elastography } \\
\text { Student's test. Data are means } \pm \mathrm{SD} \text { (min-max) }\end{array}$ \\
\hline
\end{tabular}

( $p=0.025$ and $p=0.022$, respectively) in the ON group. The mean SWE values of intraorbital fat tissue adjacent optic nerves with neuritis in the ON group exceeded the mean values in the healthy group $(1.42 \pm 0.16 \mathrm{~m} / \mathrm{s}$ and $6.57 \pm 1.15 \mathrm{kPa})(p=0.014$ and $p=0.018$, respectively $)$ (Tab. 1 and Tab. 2). There was no significant difference between the normal contralateral side of ON patients and the healthy group with regard to the mean SWE values of intraorbital fat tissue adjacent optic nerves $(p>0.05)$. No significant difference was observed between MS patients and RION patients in terms of the mean SWE values of intraorbital fat tissue adjacent optic nerves with neuritis $(1.89 \pm 0.24 \mathrm{~m} / \mathrm{s}-10.44 \pm 3.11 \mathrm{kPa}$ and $1.82 \pm 0.33 \mathrm{~m} / \mathrm{s}-$ $8.36 \pm 2.31 \mathrm{kPa}$, respectively) $(p>0.05)$. The intraobserver agreement for SWE values of intraorbital fat tissue adjacent optic nerves was excellent, with an ICC of 0.88 [95\% CI, 0.835-0.925].

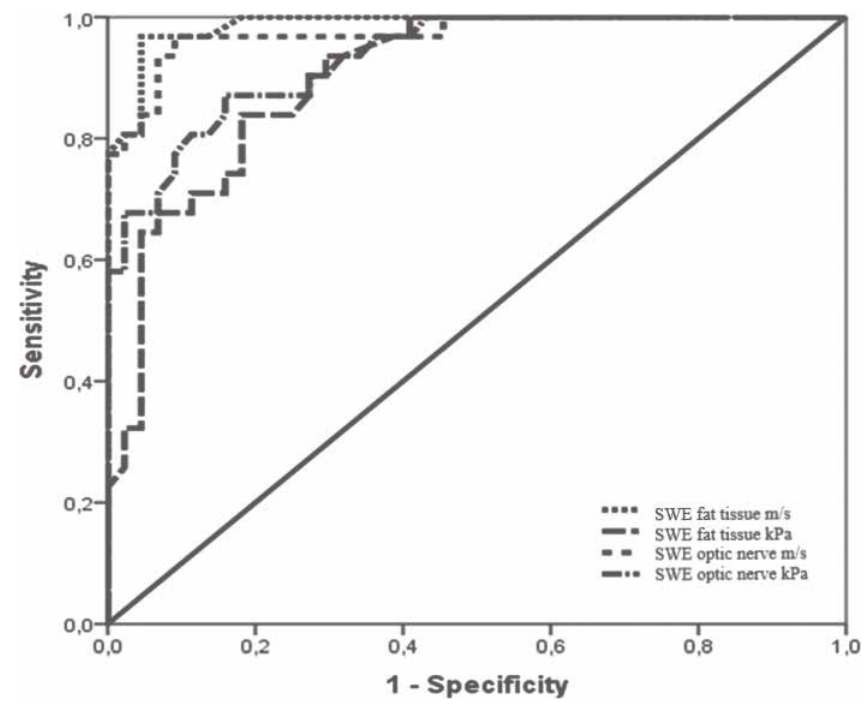

Fig. 3. ROC curve analysis showing a high diagnostic accuracy for determining ON with SWE values of the optic nerves (AUC 0.955 [95\% CI, 0.933-0.978] in m/s and AUC 0.967 [95\% CI, $0.940-0.985]$ in $\mathrm{kPa}$. ROC curve analysis also indicated a high diagnostic accuracy for determining ON with SWE values of intraorbital fat tissue adjacent optic nerves (AUC 0.945 [95\% CI, $0.935-0.965] \mathrm{in} \mathrm{m} / \mathrm{s}$ and AUC 0.954 [95\% CI, 0.936-0.975] in $\mathrm{kPa}$
Tab. 2. Comparison of the mean optic nerve diameter and SWE values between the neuritis side and normal side in the ON group ( $n=$ number of eyes)

\begin{tabular}{|c|c|c|c|}
\hline & $\begin{array}{l}\text { ON group, } \\
\text { neuritis side } \\
(n=36)\end{array}$ & $\begin{array}{l}\text { ON group, } \\
\text { normal side } \\
(n=36)\end{array}$ & $p$ \\
\hline $\begin{array}{l}\text { Optic nerve } \\
\text { diameter }\end{array}$ & $4.58 \pm 0.23 \mathrm{~cm}$ & $3.66 \pm 0.58 \mathrm{~cm}$ & 0.019 \\
\hline $\begin{array}{l}\text { Optic nerve } \\
\text { SWE value }\end{array}$ & $\begin{array}{c}2.49 \pm 0.41 \mathrm{~m} / \mathrm{s} \\
\text { and } \\
17.56 \pm 4.42 \mathrm{kPa}\end{array}$ & $\begin{array}{c}1.71 \pm 0.32 \mathrm{~m} / \mathrm{s} \\
\text { and } \\
9.02 \pm 2.34 \mathrm{kPa}\end{array}$ & $\begin{array}{c}0.003 \\
\text { and } \\
0.015\end{array}$ \\
\hline $\begin{array}{c}\text { Fat tissue } \\
\text { adjacent optic } \\
\text { nerve SWE } \\
\text { value }\end{array}$ & $\begin{array}{c}1.87 \pm 0.32 \mathrm{~m} / \mathrm{s} \\
\text { and } \\
9.65 \pm 1.12 \mathrm{kPa}\end{array}$ & $\begin{array}{c}1.47 \pm 0.27 \mathrm{~m} / \mathrm{s} \\
\text { and } \\
6.78 \pm 1.14 \mathrm{kPa}\end{array}$ & $\begin{array}{c}0.014 \\
\text { and } \\
0.018\end{array}$ \\
\hline
\end{tabular}

ROC curve analysis showed a high level of diagnostic accuracy for determining ON with SWE values of the optic nerves (AUC 0.955 [95\% CI, 0.933-0.978] in m/s and AUC 0.967 [95\% CI, 0.940-0.985] in kPa. ROC curve analysis also indicated a high level of diagnostic accuracy for determining ON with SWE values of intraorbital fat tissue adjacent optic nerves (AUC 0.945 [95\% CI, 0.935-0.965] in m/s and AUC 0.954 [95\% CI, 0.936-0.975] in kPa (Fig. 3). With cut-off values of optic nerve SWE values as $2.115 \mathrm{~m} / \mathrm{s}$ and $13.16 \mathrm{kPa}$ for determining of $\mathrm{ON}$, the sensitivity and specificity were $92.5 \%, 94.8 \%$ and $92.2 \%, 94.5 \%$, respectively. Choosing cut-off values of intraorbital fat tissue adjacent optic nerves SWE values as $1.65 \mathrm{~m} / \mathrm{s}$ and $8.22 \mathrm{kPa}$ for determining ON, sensitivity and specificity were $91.5 \%, 92.7 \%$ and $91.1 \%$, $93.5 \%$, respectively.

We detected no meaningful correlation between the optic nerve diameter and SWE values of the optic nerves $(\mathrm{r}=$ $0.105, p=0.324$ ). No significant correlation was observed between the mean time of the onset of ON attack and SWE values of the optic nerves or SWE values of intraorbital fat tissue adjacent optic nerves ( $p=0.442$ and $p=0.448$, respectively). Moreover, no significant correlations were observed between age and SWE values of the optic nerves or SWE values of intraorbital fat tissue adjacent optic nerves of the healthy controls $(p=0.352$ and $p=0.378$, respectively).

\section{Discussion}

Our study demonstrated that elastographic findings were different in the affected side of ON patients, rather than the normal sides of ON patients and healthy subjects. In our study, we found significantly higher mean SWE values of the optic nerves with neuritis than the values of the contralateral normal optic nerves in ON patients and healthy subjects. In addition, the mean SWE values of intraorbital fat tissue adjacent optic nerves with neuritis were significantly higher than the values of the contralateral normal side in the $\mathrm{ON}$ group and healthy subjects. We also detected a high diagnostic accuracy of SWE values of the optic nerves and SWE values of the intraorbital fat tissue adjacent optic nerves in determining ON. 
$\mathrm{ON}$ is an immune-mediated inflammatory condition of the optic nerve. It is frequently the initial feature of MS generally seen in young patients on admission. Acute loss of vision is often a consequence of acute demyelination of the optic nerve, and almost half of MS patients experience it at some stage of their disease. Similarly to acute MS plaques, pathological findings include myelin loss and edema in myelinated nerve sheaths. Retinal vascular endothelial inflammation can sometimes be visualized as retinal vascular sheathing ${ }^{(10)}$. Myelin loss transcends axonal loss, and the optic nerve cross-sectional area decreases after $\mathrm{ON}^{(11-13)}$.

Demyelination in $\mathrm{ON}$ is immune-mediated, but the specific mechanisms are unknown. Systemic T cell activation is identified at symptom onset, and it precedes changes in the $\mathrm{CSF}^{(14)}$. Systemic changes also normalize earlier (within two to four weeks) than central changes. T cell activation leads to the release of cytokines and other inflammatory agents. $\mathrm{B}$ cell activation against myelin basic protein can be demonstrated in the CSF of patients with $\mathrm{ON}^{(15)}$. A genetic susceptibility for $\mathrm{ON}$ is supported by an over-representation of certain human leukocyte antigen (HLA) types among patients with $\mathrm{ON}^{(16,17)}$.

Recurrent optic nerve inflammation, at least in two disseminated episodes, without any evidence of systemic or central nervous system involvement such as MS, is referred to as recurrent isolated optic neuritis (RION). Clinical and paraclinical marks may help to recognize and make a diagnosis of RION $^{(18-20)}$. Steroid dependence for preventing attacks is diagnosed as chronic recurrent isolated optic neuritis $(\mathrm{CRION})^{(21,22)}$.

$\mathrm{ON}$ is usually diagnosed on the basis of clinical findings, with added confirmation by $\mathrm{MRI}^{(23)}$. Accurate diagnosis has a critical role in starting appropriate ophthalmologic and neurologic evaluation and management. Corticosteroids are often used in treatment to prevent vision loss. MRI is an ideal technique for diagnosing and evaluating many conditions. Hyperintense signals on $\mathrm{T}_{2}$-weighted imaging and enhancement of the optic nerve on fat-suppressed $\mathrm{T}_{1}$-weighted MRI after intravenous gadolinium provide a sensitive method for demonstrating ON. In acute ON, abnormal enhancement of the optic nerve indicates a blood-optic nerve barrier breakdown in $94.4 \%$ of affected optic nerves ${ }^{(24)}$. Unfortunately, MRI also has some limitations. Therefore transorbital ultrasonography was used to evaluate optic nerve sheath diameter in several studies ${ }^{(25-27)}$. Recently, sonoelastography, a technique that allows tissue stiffness characterization, has been applied to the optic nerve. It was first described by Ophir in 1991 and widely applied in work with biological tissues by Hans Oestriecher ${ }^{(28-30)}$. SWE is produced by the transducer and obtains quantitative information on tissue elasticity. SWE is less dependent on the operator, more reproducible, and ensures quantitative results ${ }^{(31,32)}$, so it was used in our study.

We realized that the mean SWE values of the optic nerves and adjacent fat tissue with unilateral neuritis were significantly increased compared to the normal sides of the patients and healthy subjects. We consider that increased stiffness is compatible with the inflammatory process in optic nerve, and increased stiffness in adjacent fat tissue indicates that there could be accompanying inflammatory changes in these tissues in ON. Our results are consistent with the previous study reported by İnal et al. ${ }^{(12)}$. They stated that the SWE values (as $\mathrm{kPa}$ ) of MS patients were significantly higher than those of the healthy controls. In another study, Batur et al. ${ }^{(31)}$ used acoustic radiation force impulse (ARFI) imaging in their evaluation of ON with MS and idiopathic neuritis. They found significantly higher mean SWE values (as $\mathrm{m} / \mathrm{s}$ ) of the optic nerves and adjacent tissues with neuritis than in the contralateral normal side. Our results are concordant with their results.

Our study is unique in revealing optic nerve stiffness differences in patients with $\mathrm{ON}$, determining intraorbital fat tissue changes and creating quantitative SWE measurements with both $\mathrm{m} / \mathrm{s}$ and $\mathrm{kPa}$ values for both optic nerves and intraorbital fat tissue adjacent optic nerves resulting in excellent intraobserver ICC values. The results of our study offer an alternative non-invasive diagnostic method for ON patients as demonstrating the changes in elasticity of the optic nerves.

Recently, elastographic studies have been performed for ocular and periocular tissues in the human eyes, and reported some side effects ${ }^{(7,12,33-34)}$. The ocular tissues are particularly vulnerable to mechanical and thermal injury associated with excessive US energy, so the United States Food and Drug Administration (FDA) and World Federation for Ultrasound in Medicine and Biology have imposed strict thermal index (TI) and mechanical index (MI) limits for diagnostic ocular US applications $(\mathrm{TI}<1.0 \text { and } \mathrm{MI}<0.23)^{(35-36)}$. In our study, the TI values $(<0.5)$ and MI values $(<0.21)$ were below the FDA limits for ocular US applications. There were no changes in visual function before and after the SWE examination in any participants involved in the study.

The study had certain limitations. We had only two subgroups of ON patients (MS and RION), so we could not evaluate SWE values in other pathologies affecting the optic nerve. The sample sizes of the patient subgroups were relatively small, which might have had an influence on the non-significant results of comparisons of mean SWE values between these two. In addition, the US and SWE evaluations were performed by the same radiologist, so we could not calculate interobserver reliability.

\section{Conclusion}

Our study showed SWE to have a high level of diagnostic accuracy in patients with $\mathrm{ON}$. We suggest that SWE, a quantitative method which is non-invasive, and easy accessible and applicable in clinical practice, might play a diagnostic role in determining the optic nerve and adjacent fat tissue findings as an alternative to MRI in patients with ON.

\section{Conflict of interest}

The Authors do not report any financial or personal connections with other persons or organizations which might negatively affect the contents of this publication and/or claim authorship rights to this publication. 


\section{Informed consent}

A formal written informed consent was obtained from all patients enrolled.

\section{References}

1. Hoorbakht H, Bagherkashi F: Optic neuritis, its differential diagnosis and management.Open Ophthalmol J. 2012; 6: 65-72.

2. Guy J, Qi X: Chapter 7. In: Levin LA, Albert DM (ed.): Ocular Disease: Mechanisms and Management. Elsevier, Philadelphia 2010: 278-288.

3. Petzold A, Wattjes MP, Costello F, Flores-Rivera J, Fraser CL, Fujihara K et al.: The investigation of acute optic neuritis: a review and proposed protocol. Nat Rev Neurol 2014; 10: 447-458.

4. Pérez-Cambrodí RJ, Gómez-Hurtado Cubillana A, Merino-Suárez ML, Piñero-Llorens DP, Laria-Ochaita C: Optic neuritis in pediatric population: a review in current tendencies of diagnosis and management. J Optom 2014; 7: 125-130.

5. Gala F: Magnetic resonance imaging of optic nerve. Indian J Radiol Imaging 2015; 25: 421-438.

6. Bakshi R, Thompson AJ, Rocca MA, Pelletier D, Dousset V, Barkhof F et al.: MRI in multiple sclerosis: current status and future prospects. Lancet Neurol 2008; 7: 615-625.

7. Vural M, Acar D, Toprak U, Alp MN, Köz ÖG, Sayın B, Abat GK: The evaluation of the retrobulbar orbital fat tissue and optic nerve with strain ratio elastography. Med Ultrason 2015; 17: 45-48.

8. Detorakis ET, Drakonaki EE, Tsilimbaris MK, Pallikaris IG, Giarmenitis S: Real-time ultrasound elastographic imaging of ocular and periocular tissues: a feasibility study. Ophthalmic Surg Lasers Imaging 2010; 41: 135-141.

9. Thompson AJ, Banwell BL, Barkhof F, Carroll WM, Coetzee TG, Comi G et al.: Diagnosis of multiple sclerosis: 2017 revisions of the McDonald criteria. Lancet Neurol 2018; 17: 162-173.

10. Lightman S, McDonald WI, Bird AC, Francis DA, Hoskins A, Batchelor JR et al.: Retinal venous sheathing in optic neuritis. Its significance for the pathogenesis of multiple sclerosis. Brain 1987; 110: 405-414.

11. Bland JM, Altman DG: Statistical methods for assessing agreement between two methods of clinical measurement. Lancet 1986; 1: 307-310.

12. İnal M, Tan S, Yumusak EM, Şahan MH, Alpua M, Örnek K: Evaluation of the optic nerve using strain and shear wave elastography in patients with multiple sclerosis and healthy subjects. Med Ultrason 2017; 19: 39-44.

13. Graham SL, Klistorner A: Afferent visual pathways in multiple sclerosis: a review. Clin Exp Ophthalmol 2017; 45: 62-72.

14. Roed H, Frederiksen J, Langkilde A, Sørensen TL, Lauritzen M, Sellebjerg F: Systemic T-cell activation in acute clinically isolated optic neuritis. J Neuroimmunol 2005; 162: 165-172.

15. Söderström M, Link H, Xu Z, Fredriksson S: Optic neuritis and multiple sclerosis: anti-MBP and anti-MBP peptide antibody-secreting cells are accumulated in CSF. Neurology 1993; 43: 1215-1222.

16. Frederiksen JL, Madsen HO, Ryder LP, Larsson HB, Morling N, Svejgaard A: HLA typing in acute optic neuritis. Relation to multiple sclerosis and magnetic resonance imaging findings. Arch Neurol 1997; 54: 76-80.

17. Francis DA, Compston DA, Batchelor JR, McDonald WI: A reassessment of the risk of multiple sclerosis developing in patients with optic neuritis after extended follow-up. J Neurol Neurosurg Psychiatry 1987; 50: 758-765.

18. Arzani M, Sahraian MA, Rezaei H, Naser Moghadasi A: Recurrent isolated optic neuritis: a study on 22 patients. Iran J Neurol 2017; 16: 130-135.

19. Arndt C, Labauge P, Speeg-Schatz C, Jeanjean L, Fleury M, Castelnovo G et al.: Recurrent inflammatory optic neuropathy. J Fr Ophtalmol 2008; 31: 363-367.

\section{Ethical approval}

Local Institutional Review Board approval was obtained before starting the study. The study was conducted according to the World Medical Association Declaration of Helsinki

20. Petzold A, Plant GT: Diagnosis and classification of autoimmune optic neuropathy. Autoimmun Rev 2014; 13: 539-345.

21. Pérez-Díaz H, Casado JL, Uclés-Sánchez A, Saiz A: Chronic relapsing inflammatory optic neuropathy (CRION) without detection of IgGNMO antibodies. Neurologia 2007; 22: 553-555 [in Spanish].

22. Saini M, Khurana D: Chronic relapsing inflammatory optic neuropathy. Ann Indian Acad Neurol 2010; 13: 61-63.

23. Akçam HT, Capraz IY, Aktas Z, Caglayan HZ, Oktar SO, Hasanreisoglu M et al.: Multiple sclerosis and optic nerve: an analysis of retinal nerve fiber layer thickness and color Doppler imaging parameters. Eye (Lond) 2014; 28: 1206-1211

24. Kupersmith MJ, Alban T, Zeiffer B, Lefton D: Contrast-enhanced MRI in acute optic neuritis: relationship to visual performance. Brain 2002; 125: $812-822$.

25. Voss E, Raab P, Trebst C, Stangel M: Clinical approach to optic neuritis: pitfalls, red flags and differential diagnosis. Ther Adv Neurol Disord 2011; 4: 123-134.

26. Bäuerle J, Schuchardt F, Schroeder L, Egger K, Weigel M, Harloff A: Reproducibility and accuracy of optic nerve sheath diameter assessment using ultrasound compared to magnetic resonance imaging. BMC Neurol 2013; 13: 187

27. Candeliere Merlicco A, Gabaldón Torres L, Villaverde González R, Fernández Romero I, Aparicio Castro E, Lastres Arias MC: Transorbital ultrasonography for measuring optic nerve atrophy in multiple sclerosis. Acta Neurol Scand 2018; 138: 388-393.

28. Ophir J, Céspedes I, Ponnekanti H, Yazdi Y, Li X: Elastography: a quantitative method for imaging the elasticity of biological tissues. Ultrason Imaging 1991; 13: 111-134.

29. Ophir J, Cespedes I, Garra B, Ponnekanti H, Huang Y, Maklad N: Elastography: ultrasonic imaging of tissue strain and elastic modulus in vivo. Eur J Ultrasound 1996; 3: 49-70.

30. Oestreicher HL: Field and impedance of an oscillating sphere in a viscoelastic medium with an application to biophysics. J Acoust Soc Am 1951; 23: 707-714.

31. Batur M, Batur A, Çilingir V, Seven E, Çinal A, Bora A et al.: Ultrasonic elastography evaluation in optic neuritis. Semin Ophthalmol 2018; 33: 237-241.

32. Burulday V, Doğan A, Şahan MH, Arıkan Ş, Güngüneş A: Ultrasound elastography of the median nerve in patients with acromegaly: a case-control study. J Ultrasound Med 2018; 37: 2371-2377.

33. Dikici AS, Mihmanli I, Kilic F, Ozkok A, Kuyumcu G, Sultan P et al.: In vivo evaluation of the bio-mechanical properties of optic nerve and peripapillary structures by ultrasonic shear wave elastography in glaucoma. Iran J Radiol 2016; 13: e36849.

34. Özen Ö, Özer MA, Tosun A, Özen S: Evaluation of the optic nerve and scleral-choroidal-retinal layer with ultrasound elastography in glaucoma and physiological optic nerve head cupping. Med Ultrason 2018; 1: 76-79.

35. Barnett SB, Duck F, Ziskin M: WFUMB Symposium on Safety of Ultrasound in Medicine: conclusions and recommendations on biological effects and safety of ultrasound contrast agents, 2006. Ultrasound Med Biol 2007; 33: 233-234. 